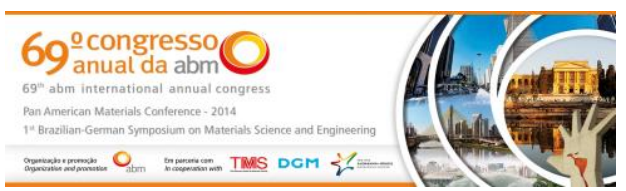

Tema: Engenharia de superfície

\title{
DESENVOLVIMENTO DE UMA BASE DE CARACTERÍSTICAS DE BIOMATERIAIS PARA AUXILIAR O CONHECIMENTO DA OSSEOINTEGRAÇÃO EM $\mathrm{TiO}_{2}{ }^{*}$
}

\section{Resumo}

\author{
Mateus Luiz Gamba \\ Daniel Basílio Marcelo² \\ Fabiano Rodrigues Fernandes ${ }^{1}$ \\ Alana Witt Hansen ${ }^{3}$ \\ Leonardo Marasca Antonini \\ Célia de Fraga Malfatti ${ }^{5}$
}

O titânio e suas ligas são aplicados em grande escala em implantes ósseos por apresentarem excelentes resultados de biocompatibilidade. No entanto, ainda não existe um consenso na literatura com relação à influência das características morfológicas destes implantes na osseointegração, principalmente na definição da melhor rugosidade e energia superficial. Vários trabalhos têm sido realizados com o intuito de comparar diferentes tratamentos superficiais empregados para otimizar a adesão, o crescimento e a proliferação celular. $\mathrm{O}$ presente trabalho tem como objetivo apresentar uma base de dados sobre características superfícies versus osseointegração para experimentos de biocompatibilidade realizados in vitro. Foram feitas coletas e análise de dados qualitativos usando métodos analíticos em artigos científicos publicados em periódicos internacionais, sendo considerados na pesquisa artigos que utilizaram superfícies de $\mathrm{Ti} / \mathrm{TiO}_{2}$ e células osteoblásticas. Os principais atributos definidos para a base de dados foram rugosidade, tamanho da célula, energia da superfície e/ou ângulo de contato, tipo de tratamento superficial, viabilidade e a resposta observada na cultura celular. Espera-se que esse artigo contribua para que futuros trabalhos possam utilizar métodos e estudos que permitam auxiliar na descoberta de conhecimento através de padrões que acelerem o processo de osseointegração impactando diretamente na recuperação do paciente implantado e na sua qualidade de vida.

Palavras-chave: Tratamento superfícies; Osseointegração; $\mathrm{TiO}_{2}$; Base de dados;

\section{DEVELOPMENT OF A BASE CHARACTERISTICS BIOMATERIALS TO AID IN KNOWLEDGE} OSSEOINTEGRATION $\mathrm{TIO}_{2}$

\section{Abstract}

Titanium and its alloys are widely used as bone implants due to their excellent biocompatibility. However there is no consensus in the literature regarding the morphological characteristics of implants influence in osseointegration, especially in defining the best roughness and surface energy. Several studies have been conducted in order to compare different employed surface treatments aiming the optimization of cell adhesion, growth and proliferation. This paper aims to introduce a database on surfaces versus osseointegration characteristics for biocompatibility experiments performed in vitro. Qualitative data were collected and analyzed applying analytical methods reported in articles published in journals regarding surface of $\mathrm{Ti} / \mathrm{TiO}_{2}$ and osteoblast cells. The main attributes defined for the database were: roughness, cell size, surface energy and/or contact angle, type of surface treatment, viability and the response of cell culture. It is expected that this paper contributes to the future works in the discovery of knowledge through standards to accelerate the osseointegration process, directly impacting on the recovery and life quality of the implanted patients.

Keywords: Surface treatments; Osseointegration; $\mathrm{TiO}_{2}$; Database;

\footnotetext{
Bacharel em Ciência da Computação, Mestrando, Universidade Federal do Rio Grande do Sul (UFRGS), Porto Alegre, RS, Brasil.

2 Bacharel em Sistema da Informação, Mestrando, Universidade Federal do Rio Grande do Sul (UFRGS), Porto Alegre, RS, Brasil.

3 Biomédica, Mestranda, Depto. de Engenharia, Laboratório de Pesquisa em Corrosão (Lapec), UFRGS, Porto Alegre, RS, Brasil.

4 Msc. Químico Industrial, Depto. de Engenharia, Lapec, UFRGS, Porto Alegre, RS, Brasil.

5 Engenheira Metalúrgica. Dr. Coordenadora. Depto. de Engenharia, Lapec, UFRGS, Porto Alegre, RS, Brasil.
}

\footnotetext{
* Contribuição técnica ao 69 Congresso Anual da ABM - Internacional e ao $14^{\circ}$ ENEMET - Encontro Nacional de Estudantes de Engenharia Metalúrgica, de Materiais e de Minas, 21 a 25 de julho de 2014, São Paulo, SP, Brasil.
} 


\section{INTRODUÇÃO}

Dentre os diversos materiais utilizados com finalidades biomédicas, destaca-se atualmente o titânio (Ti) e suas ligas, por ser um material biocompatível e que apresenta boa resistência à fadiga e a corrosão. Essas características levam-no a ser principalmente empregados na fabricação de próteses ortopédicas e implantes dentários [1].

Existem vários métodos para acelerar o processo de osseointegração do $\mathrm{Ti}$, visto que naturalmente sua superfície não apresenta esta propriedade. Pesquisadores têm procurado modificar a superfície do Ti, por processos físicos e químicos, com o objetivo de diminuir o tempo de osseointegração de um implante [2].

Interações entre biomateriais e células dependem principalmente das características da superfície do material, tais como a energia superficial, a composição química, a estrutura, a rugosidade, a topografia e as condições dos fluidos ambientais [3].

Em indivíduos saudáveis, a osseointegração ocorre de modo regular, porém em indivíduos que apresentam patologias, este processo é prejudicado [4]. Dessa forma o desenvolvimento de superfícies de implantes que acelerem a osseointegração se faz necessário.

Neste contexto, a partir do presente trabalho pretende-se apresentar uma comparação entre os resultados obtidos em diferentes experimentos realizados in vitro sobre uma superfície de $\mathrm{Ti} / \mathrm{TiO}_{2}$, avaliando-se para isso as características superficiais versus a osseointegração. Pretende-se, a partir desse levantamento, obter uma base de dados que possa contribuir para o entendimento do efeito das características da superfície sobre o processo de osseointegração.

\section{MATERIAIS E MÉTODOS}

As coletas de dados para elaboração da base de dados baseou-se em análises qualitativas dos métodos analíticos utilizados em artigos científicos publicados em periódicos internacionais.

Foram utilizados somente periódicos internacionais da plataforma Science Direct, sendo que atualmente o Science Direct possui mais de 2.500 revistas científicas, mais de 20.000 livros e mais de 12 milhões de artigos nas áreas científica, tecnológica e médica, representando aproximadamente $25 \%$ da produção científica mundial [5].

As principais palavras chaves utilizadas para o filtro da pesquisa foram: $\mathrm{TiO}_{2}$, osteoblasts e surfaces; $\mathrm{TiO}_{2}$, osteoblasts e roughness; $\mathrm{TiO}_{2}$, osteoblasts e wettability.

Dentre os 1700 artigos encontrados, até o momento foram utilizados os seguintes: Feng et al. [3], Györgyey et al. [4], Neupane et al. [6], Hori et al. [7], Qu et al. [8], Sugita et al. [9], Brammer et al. [10] e An et al.[11], os quais apresentam um monitoramento mais completo das propriedades que estavam sendo avaliadas no presente estudo.

A primeira etapa foi determinar as principais características superficiais que facilitam a biofixação dos osteoblastos em superfície de $\mathrm{Ti} / \mathrm{TiO}_{2}$. Essas características foram definidas a partir dos resultados obtidos por diferentes artigos [1-4,6-13].

A segunda etapa consistiu na pesquisa e estudo de artigos que cumpriram os requisitos para que fossem inseridos na tabela da base de dados e a terceiro etapa foi à extração, análise e inserção dos valores na tabela.

* Contribuição técnica ao 69 Congresso Anual da ABM - Internacional e ao 14ํㅡㄹ ENEMET - Encontro Nacional de Estudantes de Engenharia Metalúrgica, de Materiais e de Minas, 21 a 25 de julho de 2014, São Paulo, SP, Brasil. 


\section{RESULTADOS E DISCUSSÃO}

As informações retiradas dos artigos [3,4,6-11] foram organizadas em quatro grupos principais: descrição, parâmetros dependentes do tratamento de superfície, variáveis do ensaio in vitro e resposta da osseointegração in vitro.

O primeiro grupo, identificado como descrição, está contido em todas as tabelas, como forma de correlacionar os grupos entre si.

Os parâmetros dependentes do tratamento de superfície (Tabela 1), formaram o segundo grupo, que foi dividido nas seguintes colunas: estrutura, rugosidade (Ra), energia superficial, ângulo de contato (água) e caráter hidrofílico ou hidrofóbico.

O terceiro grupo foi composto pelas variáveis do ensaio in vitro (Tabela 2): origem das células osteoblásticas, solução utilizada na cultura de células, tempo de duração do ensaio.

Os resultados da cultura celular foram avaliados através do ensaio de proliferação celular (MTT), que quantifica espectrofotometricamente o crescimento, a viabilidade e a proliferação celular, e de atividade da fosfatase alcalina (ALP), que é sintetizada pelos osteoblastos, e está envolvida nos processos de formação e mineralização óssea (Tabela 3).

Tabela 1. Parâmetros Dependentes do Tratamento de Superfície

\begin{tabular}{|c|c|c|c|c|c|c|}
\hline \multirow[t]{2}{*}{ Tratamento } & \multirow[t]{2}{*}{ Estrutura } & \multicolumn{2}{|c|}{$\begin{array}{l}\text { Rugosidade } \\
\quad \text { (Ra) }\end{array}$} & \multirow[t]{2}{*}{$\begin{array}{l}\text { Energia } \\
\text { Superficial }\end{array}$} & \multirow{2}{*}{$\begin{array}{l}\text { Ângulo } \\
\text { de } \\
\text { Contato } \\
\text { (solução: } \\
\text { água) }\end{array}$} & \multirow[t]{2}{*}{$\begin{array}{l}\text { Caráter } \\
\text { Hidrofílico ou } \\
\text { Hidrofóbico }\end{array}$} \\
\hline & & $\begin{array}{l}\text { Nano } \\
(\mathrm{nm})\end{array}$ & $\begin{array}{l}\text { Micro } \\
(\mu \mathrm{m})\end{array}$ & & & \\
\hline $\begin{array}{l}\text { Lixada com } \quad \mathrm{Al}_{2} \mathrm{O}_{3} \text { até } \\
\text { grana } 120[3]\end{array}$ & $\begin{array}{l}\text { Camada } \\
\text { Natural de } \\
\mathrm{TiO}_{2}\end{array}$ & & 0,09 & $33 \mathrm{~mJ} \cdot \mathrm{m}^{-2}$ & & \\
\hline $\begin{array}{l}\text { Lixada com } \mathrm{Al}_{2} \mathrm{O}_{3} \text { até } \\
\text { grana } 120 \text { e tratado } \\
\text { termicamente a } 600^{\circ} \mathrm{C} \text { por } \\
30 \text { minutos ao ar }[3]\end{array}$ & $\begin{array}{c}\text { Camada de } \\
\mathrm{TiO}_{2} \text { formada } \\
\text { por tratamento } \\
\text { térmico } \\
\end{array}$ & & 0,21 & $35 \mathrm{~mJ} \cdot \mathrm{m}^{-2}$ & & \\
\hline $\begin{array}{l}\text { Lixada com } \mathrm{Al}_{2} \mathrm{O}_{3} \text { até } \\
\text { grana } 120 \text { e tratado } \\
\text { termicamente a } 600^{\circ} \mathrm{C} \text { por } \\
30 \text { minutos em oxigênio } \\
\text { corrente }(90 \%) \text { a } 0,5 \mathrm{~L} / \mathrm{m} \\
{[3]}\end{array}$ & $\begin{array}{l}\text { Camada de } \\
\mathrm{TiO}_{2} \text { formada } \\
\text { por tratamento } \\
\text { térmico }\end{array}$ & & 0,26 & $34 \mathrm{~mJ} \cdot \mathrm{m}^{-2}$ & & \\
\hline $\begin{array}{l}\text { Lixada com } \mathrm{Al}_{2} \mathrm{O}_{3} \text { até } \\
\text { grana } 120 \text { e tratado } \\
\text { termicamente a } 600^{\circ} \mathrm{C} \text { por } \\
30 \text { minutos em vapor } \\
\text { d'água com } 1,13-1,15 \times 10^{5} \\
\mathrm{~Pa}[3]\end{array}$ & $\begin{array}{l}\text { Camada de } \\
\mathrm{TiO}_{2} \text { formada } \\
\text { por tratamento } \\
\text { térmico }\end{array}$ & & 0,3 & $38 \mathrm{~mJ} \cdot \mathrm{m}^{-2}$ & & \\
\hline $\begin{array}{l}\text { Tratadas com jato de areia } \\
\text { e ataque químico [4] }\end{array}$ & $\begin{array}{c}\text { Camada } \\
\mathrm{Natural} \mathrm{de} \\
\mathrm{TiO}_{2}\end{array}$ & 544 & & & & \\
\hline $\begin{array}{l}\text { Tratadas com jato de areia } \\
\text { e ataque químico + } \\
\text { irradiados ao laser } \\
\text { Nd:YAG Laser Ablated } \\
(532 \mathrm{~nm}, 1.3 \mathrm{~J} / \mathrm{cm} 2,10 \mathrm{~ns} \text {, }\end{array}$ & $\begin{array}{c}\text { Camada } \\
\text { Natural de } \\
\mathrm{TiO}_{2}\end{array}$ & 275 & & & & \\
\hline
\end{tabular}

* Contribuição técnica ao 69 Congresso Anual da ABM - Internacional e ao 14º ENEMET - Encontro Nacional de Estudantes de Engenharia Metalúrgica, de Materiais e de Minas, 21 a 25 de julho de 2014, São Paulo, SP, Brasil. 
200 pulses) [4]

Tratadas com jato de areia $\mathrm{e}$ ataque químico irradiados ao laser $\mathrm{KrF}$ excimer laser Ablated (248 $\mathrm{nm}$, fluence $0.4 \mathrm{~J} / \mathrm{cm} 2$, FWHM 18 ns, 2000

Camada

Natural de $\mathrm{TiO}_{2}$

288 pulses) [4]

Polido por papéis de $\mathrm{SiC}$ com grana 220-800 (Ti) [6]

Lixado por papéis de SiC
com grana $220-800+$
topografia formada de
nanotubo sem adição de
um surfactante (TN) [6]

Lixado por papéis de SiC com grana 220-800 + Matrizes nanotubular com adição de brometo de cetiltrimetilamónio (CTABTN) [6]

Lixado por papéis de SiC com grana 220-800 + Nanotubos com adição de sulfato de sódio dodecil (SDS-TN) [6]

.

Camada
Natural de
$\mathrm{TiO}_{2}$

Anodização +

Nanotubos

TiO2 diâmetro

médio $80 \mathrm{~nm}$

comprimento

$550 \mathrm{~nm}$

espessura da

parede $20 \mathrm{~nm}$

Anodização +

Nanotubos

TiO2 diâmetro

médio $75 \mathrm{~nm}$

comprimento

$0,13 \quad 27,928 \mathrm{~mJ}$

102.9 Hidrofóbico

$750 \mathrm{~nm}$

espessura da

parede $28 \mathrm{~nm}$

Anodização +

diâmetro

médio $65 \mathrm{~nm}$

comprimento

$800 \mathrm{~nm}$

espessura da

parede $28 \mathrm{~nm}$

\begin{tabular}{|c|c|c|c|c|}
\hline Usinada suavemente [7] & $\begin{array}{l}\text { Camada } \\
\mathrm{Natural} \mathrm{de} \\
\mathrm{TiO}_{2}\end{array}$ & 0,17 & & \\
\hline $\begin{array}{l}\text { Usinada suavemente }+ \\
\text { ataque químico de } 3 \% \mathrm{HF} \\
\text { e } 66 \% \mathrm{H}_{2} \mathrm{SO}_{4} \text { (Micropitted) } \\
{[7]}\end{array}$ & $\begin{array}{l}\text { Camada } \\
\text { Natural de } \\
\mathrm{TiO}_{2}\end{array}$ & 0,35 & & \\
\hline $\begin{array}{l}\text { Usinada suavemente + } \\
\text { ataque químico de } 3 \% \mathrm{HF} \\
\text { e } 66 \% \mathrm{H}_{2} \mathrm{SO}_{4} \text { (Micropitted) } \\
\text { + pulverização catódica do } \\
\text { nanonodule [7] }\end{array}$ & $\begin{array}{c}\text { Nanonodule } \\
\text { de alta- } \\
\text { montagem } 200 \\
\text { nm de } \mathrm{TiO}_{2}\end{array}$ & 1,35 & & \\
\hline $\begin{array}{l}\text { Revestimento Liso de } \mathrm{TiO}_{2} \\
\text { por Ultra short pulsed laser } \\
\text { deposition (USPLD) [8] }\end{array}$ & $\begin{array}{c}\text { Camada } \\
\text { Natural de } \\
\mathrm{TiO}_{2}\end{array}$ & 20 & $114^{\circ}$ & Hidrofóbico \\
\hline $\begin{array}{l}\text { Revestimento Liso de } \\
\text { TiO2 por Ultra short pulsed } \\
\text { laser deposition (USPLD) } \\
{[8]}\end{array}$ & $\begin{array}{l}\text { Camada } \\
\text { Natural de } \\
\mathrm{TiO}_{2}\end{array}$ & 60 & $115^{\circ}$ & Hidrofóbico \\
\hline $\begin{array}{l}\text { Ataque químico com } 66 \% \\
\mathrm{H}_{2} \mathrm{SO}_{4}[9]\end{array}$ & $\begin{array}{l}\text { Nanopartícula } \\
\mathrm{s} \text { de } \mathrm{TiO}_{2} \text { com } \\
\text { diâmetro } \\
\text { médio de } 120 \\
\mathrm{~nm} \\
\end{array}$ & 0,17 & $54^{\circ}$ & Hidrofílico \\
\hline
\end{tabular}

* Contribuição técnica ao 69ำ Congresso Anual da ABM - Internacional e ao 14ํㅡㄹ ENEMET - Encontro Nacional de Estudantes de Engenharia Metalúrgica, de Materiais e de Minas, 21 a 25 de julho de 2014, São Paulo, SP, Brasil. 
Tabela 2. Variáveis do Ensaio in vitro

\begin{tabular}{|c|c|c|c|}
\hline Tratamento & $\begin{array}{l}\text { Origem das } \\
\text { células } \\
\text { osteoblásticas }\end{array}$ & Solução utilizada na cultura de células & $\begin{array}{l}\text { Tempo de } \\
\text { ensaio de } \\
\text { cultura }\end{array}$ \\
\hline $\begin{array}{l}\text { Lixada com } \mathrm{Al}_{2} \mathrm{O}_{3} \text { até grana } \\
120[3]\end{array}$ & Coelho & $\begin{array}{c}\mathrm{F}-12+100 \mathrm{IU} / \mathrm{ml} \text { de penicilina }+ \\
100 \mathrm{IU} / \mathrm{ml} \text { estreptomicina }+10 \% \text { FCS }\end{array}$ & 24 horas \\
\hline $\begin{array}{l}\text { Lixada com } \mathrm{Al}_{2} \mathrm{O}_{3} \text { até grana } \\
120 \text { e tratado termicamente a } \\
600^{\circ} \mathrm{C} \text { por } 30 \text { minutos ao ar [3] }\end{array}$ & Coelho & $\begin{array}{c}\mathrm{F}-12+100 \mathrm{IU} / \mathrm{ml} \text { de penicilina }+ \\
100 \mathrm{IU} / \mathrm{ml} \text { estreptomicina }+10 \% \text { FCS }\end{array}$ & 24 horas \\
\hline
\end{tabular}

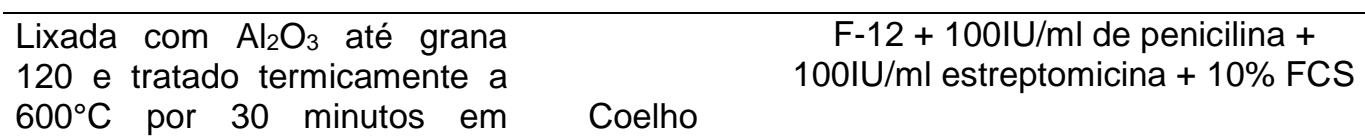

24 horas oxigênio corrente (90\%) a 0,5 L/m [3]

Lixada com $\mathrm{Al}_{2} \mathrm{O}_{3}$ até grana 120 e tratado termicamente a $600^{\circ} \mathrm{C}$ por 30 minutos em vapor d'água com $1,13-1,15 \times 10^{5} \mathrm{~Pa}$ [3]

\begin{tabular}{|c|c|c|c|}
\hline $\begin{array}{l}\text { Tratadas com jato de areia e } \\
\text { ataque químico [4] }\end{array}$ & MG-63 & $\begin{array}{c}\text { EMEM + FBS + penicilina / } \\
\text { estreptomicina + L-glutamina }\end{array}$ & 72 horas \\
\hline $\begin{array}{l}\text { Tratadas com jato de areia e } \\
\text { ataque químico + irradiados ao } \\
\text { laser Nd:YAG Laser Ablated } \\
\text { (532 nm, } 1.3 \mathrm{~J} / \mathrm{cm} 2,10 \mathrm{~ns}, 200 \\
\text { pulses) [4] }\end{array}$ & MG-63 & $\begin{array}{c}\text { EMEM + FBS + penicilina / } \\
\text { estreptomicina + L-glutamina }\end{array}$ & 72 horas \\
\hline $\begin{array}{l}\text { Tratadas com jato de areia e } \\
\text { ataque químico + irradiados ao } \\
\text { laser KrF excimer laser Ablated } \\
\text { (248 nm, fluence } 0.4 \mathrm{~J} / \mathrm{cm} 2 \text {, } \\
\text { FWHM } 18 \mathrm{~ns}, 2000 \text { pulses) [4] }\end{array}$ & MG-63 & $\begin{array}{c}\text { EMEM + FBS + penicilina / } \\
\text { estreptomicina + L-glutamina }\end{array}$ & 72 horas \\
\hline $\begin{array}{l}\text { Polido por papéis de SiC com } \\
\text { grana } 220-800 \text { (Ti) [6] }\end{array}$ & MC3TE-E1 & $\begin{array}{l}\alpha-M E M+10 \% \text { FBS }+1 \% \\
\text { penicilina/estreptomicina }\end{array}$ & 24 horas \\
\hline $\begin{array}{l}\text { Polido por papéis de SiC com } \\
\text { grana } 220-800+\text { Anodização + } \\
\text { topografia formada de } \\
\text { nanotubo sem adição de um } \\
\text { surfactante (TN) [6] }\end{array}$ & MC3TE-E1 & $\begin{array}{l}\alpha-M E M+10 \% \text { FBS }+1 \% \\
\text { penicilina/estreptomicina }\end{array}$ & 24 horas \\
\hline $\begin{array}{l}\text { Polido por papéis de SiC com } \\
\text { grana 220-800 + Anodização + } \\
\text { Matrizes nanotubular com } \\
\text { adição de brometo de } \\
\text { cetiltrimetilamónio (CTAB-TN) } \\
\text { [6] }\end{array}$ & MC3TE-E1 & $\begin{array}{l}\alpha-M E M+10 \% \text { FBS }+1 \% \\
\text { penicilina/estreptomicina }\end{array}$ & 24 horas \\
\hline $\begin{array}{l}\text { Polido por papéis de SiC com } \\
\text { grana } 220-800+\text { Anodização + } \\
\text { Nanotubos com adição de } \\
\text { sulfato de sódio dodecil (SDS- }\end{array}$ & MC3TE-E1 & $\begin{array}{l}\alpha-M E M+10 \% \text { FBS }+1 \% \\
\text { penicilina/estreptomicina }\end{array}$ & 24 horas \\
\hline
\end{tabular}
TN) [6]

$\begin{array}{ccc}\text { Coelho } & \mathrm{F}-12+100 \mathrm{IU} / \mathrm{ml} \text { de penicilina }+ \\ 100 \mathrm{IU} / \mathrm{ml} \text { estreptomicina }+10 \% \mathrm{FCS} & 24 \text { horas }\end{array}$
$100 \mathrm{IU} / \mathrm{ml}$ estreptomicina $+10 \%$ FCS 
Usinada suavemente + ataque químico de $3 \% \mathrm{HF}$ e $66 \%$ $\mathrm{H}_{2} \mathrm{SO}_{4}$ (Micropitted) [7]
$\alpha-M E M+15 \%$ FBS a $50 \mathrm{mg} / \mathrm{ml} \mathrm{de}$ ácido ascórbico + $10 \mathrm{mM} \mathrm{Na- \beta}$ glicerofosfato $+10^{-8} \mathrm{M}+$ dexametasona solução de antibióticoantimicótico contendo 10.000

unidades $/ \mathrm{ml}$ de penicilina $\mathrm{G}$ sódio, $10000 \mathrm{mg} / \mathrm{ml}$ de sulfato de estreptomicina $+25 \mathrm{mg} / \mathrm{ml}$ de anfotericina $\mathrm{B}$.

$\alpha-M E M+15 \%$ FBS a $50 \mathrm{mg} / \mathrm{ml}$ de ácido ascórbico + $10 \mathrm{mM} \mathrm{Na- \beta}$ glicerofosfato $+10^{-8} \mathrm{M}+$

Usinada suavemente + ataque químico de $3 \%$ HF e $66 \%$ $\mathrm{H}_{2} \mathrm{SO}_{4}$ (Micropitted) + pulverização catódica do

Ratazana nanonodule [7]

dexametasona solução de antibióticoantimicótico contendo 10.000 unidades $/ \mathrm{ml}$ de penicilina $\mathrm{G}$ sódio, $10000 \mathrm{mg} / \mathrm{ml}$ de sulfato de estreptomicina $+25 \mathrm{mg} / \mathrm{ml} \mathrm{de}$ anfotericina $\mathrm{B}$.

\begin{tabular}{lll}
\hline \multicolumn{3}{l}{ Revestimento Liso de TiO2 por } \\
Ultra short pulsed laser & SaOs-2 \\
deposition (USPLD) [8] & \\
\hline \multicolumn{2}{l}{ Revestimento Liso de TiO2 por } & \\
Ultra short pulsed laser & SaOs-2 \\
deposition (USPLD) [8] & & \\
\hline
\end{tabular}

Ataque químico com $66 \%$ $\mathrm{H}_{2} \mathrm{SO}_{4}$ [9]

Ratazana

\section{a-MEM + FBS + penicilina /} estreptomicina + L-glutamina

48 horas

$\alpha-M E M+F B S+$ penicilina / estreptomicina + L-glutamina

48 horas

$\alpha-M E M+15 \%$ FBS + $50 \mathrm{mg} / \mathrm{ml}$ ácido ascórbico + $10 \mathrm{mM}$ de Na- $\beta$ glicerofosfato $+108 \mathrm{M}$ de dexametasona e solução de

48 horas antibiótico / antimicótico.

\begin{tabular}{|c|c|c|c|}
\hline Ti [10] & МС3Т3-Е1 & $\begin{array}{c}\text { a-MEM + 10\% FBS }+1 \% \text { penicillin- } \\
\text { streptomycin }\end{array}$ & 48 horas \\
\hline $\begin{array}{l}\mathrm{Ti}+\text { nanotubos preparadas } \\
\text { numa proporção volumétrica } \\
1: 7 \text { de ácido acético }+0,5 \% \mathrm{w} / \mathrm{v} \\
\text { ácido fluorídrico em água }+5 \text {, } \\
10,15 \text { e } 20 \mathrm{~V} \text { durante } 30 \\
\text { minutos [10] }\end{array}$ & МС3Т3-Е1 & $\begin{array}{c}\text { a-MEM }+10 \% \text { FBS }+1 \% \text { penicillin- } \\
\text { streptomycin }\end{array}$ & 48 horas \\
\hline $\begin{array}{l}\mathrm{Ti}+\text { nanotubos preparadas } \\
\text { numa proporção volumétrica } \\
1: 7 \text { de ácido acético }+0,5 \% \mathrm{w} / \mathrm{v} \\
\text { ácido fluorídrico em água }+5 \text {, } \\
10,15 \text { e } 20 \mathrm{~V} \text { durante } 30 \\
\text { minutos [10] }\end{array}$ & МС3Т3-E1 & $\begin{array}{c}\text { a-MEM }+10 \% \text { FBS }+1 \% \text { penicillin- } \\
\text { streptomycin }\end{array}$ & 48 horas \\
\hline $\begin{array}{l}\mathrm{Ti}+\text { nanotubos preparadas } \\
\text { numa proporção volumétrica } \\
1: 7 \text { de ácido acético }+0,5 \% \mathrm{w} / \mathrm{v} \\
\text { ácido fluorídrico em água }+5 \text {, } \\
10,15 \text { e } 20 \mathrm{~V} \text { durante } 30 \\
\text { minutos [10] }\end{array}$ & МС3Т3-E1 & $\begin{array}{c}\text { a-MEM }+10 \% \text { FBS }+1 \% \text { penicillin- } \\
\text { streptomycin }\end{array}$ & 48 horas \\
\hline $\begin{array}{l}\mathrm{Ti}+\text { nanotubos preparadas } \\
\text { numa proporção volumétrica } \\
1: 7 \text { de ácido acético }+0,5 \% \mathrm{w} / \mathrm{v} \\
\text { ácido fluorídrico em água }+5 \text {, } \\
10,15 \text { e } 20 \mathrm{~V} \text { durante } 30 \\
\text { minutos [10] }\end{array}$ & МС3Т3-E1 & $\begin{array}{c}\text { a-MEM }+10 \% \text { FBS }+1 \% \text { penicillin- } \\
\text { streptomycin }\end{array}$ & 48 horas \\
\hline $\begin{array}{l}\text { Nano-cristalina, pré-tratada } \\
\text { com lixa até grana 1500, } \\
\text { anodizada com densidade de } \\
\text { corrente galvanostática igual a } \\
20 \mathrm{~A} / \mathrm{m}^{2} \text { em eletrólito } 1 \mathrm{M} \mathrm{de}\end{array}$ & Rato & $\begin{array}{c}\alpha-M E M+10 \% \text { FBS }+1 \% \text { de } \\
\text { penicilina/estreptomicina e } 1 \% \text { de I- } \\
\text { glutamina a } 200 \mathrm{ml}\end{array}$ & 48 horas \\
\hline
\end{tabular}

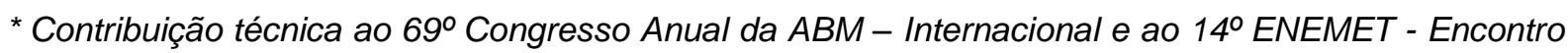
Nacional de Estudantes de Engenharia Metalúrgica, de Materiais e de Minas, 21 a 25 de julho de 2014, São Paulo, SP, Brasil. 
$\mathrm{Na}_{2} \mathrm{SO}_{4}$ e $0,5 \%$ de $\mathrm{NaF}[11]$

Micro-cristalina, pré-tratada com lixa até grana 1500 , anodizada com densidade de corrente galvanostática igual a

a-MEM + 10\% FBS + 1\% de

Rato penicilina/estreptomicina e $1 \%$ de I- 48 horas glutamina a $200 \mathrm{ml}$

Tabela 3. Resposta de Osseointegração in vitro

\begin{tabular}{|c|c|c|}
\hline \multirow{2}{*}{ Tratamento } & \multicolumn{2}{|c|}{ Viabilidade } \\
\hline & MTT & ALP \\
\hline Lixada com $\mathrm{Al}_{2} \mathrm{O}_{3}$ até grana 120 [3] & & $1,9 / \mathrm{U} / \mathrm{L}$ \\
\hline $\begin{array}{l}\text { Lixada com } \mathrm{Al}_{2} \mathrm{O}_{3} \text { até grana } 120 \text { e tratado termicamente } \\
\text { a } 600^{\circ} \mathrm{C} \text { por } 30 \mathrm{~m} \text { ao ar [3] }\end{array}$ & & $3,5 / \mathrm{U} / \mathrm{L}$ \\
\hline $\begin{array}{l}\text { Lixada com } \mathrm{Al}_{2} \mathrm{O}_{3} \text { até grana } 120 \text { e tratado termicamente } \\
\text { a } 600^{\circ} \mathrm{C} \text { por } 30 \text { minutos em oxigênio corrente }(90 \%) \text { a } \\
0,5 \mathrm{~L} / \mathrm{m}[3]\end{array}$ & & $4,4 / \mathrm{U} / \mathrm{L}$ \\
\hline $\begin{array}{l}\text { Lixada com } \mathrm{Al}_{2} \mathrm{O}_{3} \text { até grana } 120 \text { e tratado termicamente } \\
\text { a } 600^{\circ} \mathrm{C} \text { por } 30 \text { minutos em vapor d'água com } 1,13- \\
1,15 \times 10^{5} \mathrm{~Pa}[3]\end{array}$ & & $2,6 / U / L$ \\
\hline Tratadas com jato de areia e ataque químico [4] & 0,410 & 0,203 \\
\hline $\begin{array}{l}\text { Tratadas com jato de areia e ataque químico + irradiados } \\
\text { ao laser Nd:YAG Laser Ablated }(532 \mathrm{~nm}, 1.3 \mathrm{~J} / \mathrm{cm} 2,10 \\
\text { ns, } 200 \text { pulses) [4] }\end{array}$ & 0,403 & 0,184 \\
\hline $\begin{array}{l}\text { Tratadas com jato de areia e ataque químico + irradiados } \\
\text { ao laser KrF excimer laser Ablated ( } 248 \mathrm{~nm} \text {, fluence } 0.4 \\
\mathrm{~J} / \mathrm{cm} 2, \mathrm{FWHM} 18 \mathrm{~ns}, 2000 \text { pulses) [4] }\end{array}$ & 0,372 & 0,199 \\
\hline Polido por papéis de SiC com grana $220-800$ (Ti) [6] & & 0,31 \\
\hline $\begin{array}{l}\text { Polido por papéis de SiC com grana } 220-800+ \\
\text { Anodização + topografia formada de nanotubo sem } \\
\text { adição de um surfactante (TN) [6] }\end{array}$ & 0,34 & 0,69 \\
\hline
\end{tabular}

Polido por papéis de SiC com grana 220-800 +

$\begin{array}{lll}\text { Anodização + Matrizes nanotubular com adição de } & 0,31 & 0,37\end{array}$

brometo de cetiltrimetilamónio (CTAB-TN) [6]

Polido por papéis de SiC com grana 220-800 +

Anodização + Nanotubos com adição de sulfato de sódio

dodecil (SDS-TN) [6]

Usinada suavemente [7]

0,17

Usinada suavemente + ataque químico de $3 \% \mathrm{HF}$ e $66 \%$

$\mathrm{H}_{2} \mathrm{SO}_{4}$ (Micropitted) [7]

0,27

Usinada suavemente + ataque químico de 3\% HF e $66 \%$

$\mathrm{H}_{2} \mathrm{SO}_{4}$ (Micropitted) + pulverização catódica do

0,28

nanonodule [7]

Revestimento Liso de TiO2 por Ultra short pulsed laser

deposition (USPLD) [8]

Revestimento Liso de TiO2 por Ultra short pulsed laser

deposition (USPLD) [8]

Ataque químico com $66 \% \mathrm{H}_{2} \mathrm{SO}_{4}[9]$

0,3

$\mathrm{Ti}[10]$

]

1,22

$\mathrm{Ti}+$ nanotubos preparadas numa proporção volumétrica

$1: 7$ de ácido acético $+0,5 \% \mathrm{w} / \mathrm{v}$ ácido fluorídrico em

água $+5,10,15$ e $20 \mathrm{~V}$ durante 30 minutos [10]

$\mathrm{Ti}+$ nanotubos preparadas numa proporção volumétrica

$1: 7$ de ácido acético $+0,5 \% \mathrm{w} / \mathrm{v}$ ácido fluorídrico em água $+5,10,15$ e $20 \mathrm{~V}$ durante 30 minutos [10]

1,92

$0,09 \quad 0,21 \mathrm{mmol} / \mathrm{hour} / \mathrm{\mu g}$

0,2

$0,36 \mathrm{mmol} / \mathrm{hour} / \mathrm{\mu g}$ protein

* Contribuição técnica ao 69ํㅡㄹ Congresso Anual da ABM - Internacional e ao 14 ENEMET - Encontro Nacional de Estudantes de Engenharia Metalúrgica, de Materiais e de Minas, 21 a 25 de julho de 2014, São Paulo, SP, Brasil. 
$\mathrm{Ti}+$ nanotubos preparadas numa proporção volumétrica

$1: 7$ de ácido acético $+0,5 \% \mathrm{w} / \mathrm{v}$ ácido fluorídrico em água $+5,10,15$ e $20 \mathrm{~V}$ durante 30 minutos [10]

0,175

$\mathrm{Ti}+$ nanotubos preparadas numa proporção volumétrica

$1: 7$ de ácido acético $+0,5 \% \mathrm{w} / \mathrm{v}$ ácido fluorídrico em

água $+5,10,15$ e $20 \mathrm{~V}$ durante 30 minutos [10]

Nano-cristalina, pré-tratada com lixa até grana 1500, anodizada com densidade de corrente galvanostática igual a $20 \mathrm{~A} / \mathrm{m}^{2}$ em eletrólito $1 \mathrm{M}$ de $\mathrm{Na}_{2} \mathrm{SO}_{4}$ e $0,5 \%$ de

$\mathrm{NaF}[11]$

Micro-cristalina, pré-tratada com lixa até grana 1500 ,

anodizada com densidade de corrente galvanostática igual a $70 \mathrm{~A} / \mathrm{m}^{2} \mathrm{em}$ meio aquoso [11]

O resultado preliminar de mapeamento de resposta do crescimento celular é consequência do tratamento de superfície empregado no Ti. Na Tabela 1, a coluna Caráter Hidrofílico ou Hidrofóbico foi preenchida conforme ângulo de contato, considerando hidrofílica quando este for menor que $60^{\circ}$ graus e hidrofóbico quando maior [9]. Estudos demonstraram que superfícies com caráter hidrofílico apresentam melhor adesão e por consequência melhor proliferação e crescimento celular [6].

Nem todos os artigos avaliam a influência simultânea da nano e da micro rugosidade, sendo que de acordo com alguns autores, esses dois parâmetros influenciam o crescimento celular [11]. A rugosidade da superfície, tanto na escala nano quanto na escala micro, é de extrema importância para a adesão celular. De acordo com alguns autores [12], de modo geral, a rugosidade nanométrica aumenta a molhabilidade, influenciando positivamente na adesão e proliferação celular, favorecendo uma osseointegração mais rápida.

Além do caráter hidrofílico ou hidrofóbico e rugosidade, a estrutura de $\mathrm{TiO}_{2}$ formada na superfície, em formato de nanotubos, também tem influência no crescimento celular. A existência de nanotubos promove uma melhor fixação de osteoblastos e crescimento ósseo [6].

A partir das Tabelas 1, 2 e 3, verificou-se que mesmo o substrato $\left(\mathrm{Ti}_{\mathrm{i}} \mathrm{TiO} 2\right)$ e o tipo celular (osteoblasto) sendo mantidos constantes, os resultados de adesão, crescimento e proliferação celular, mensurados pelos testes de MTT e ALP, apresentaram variação. Pode-se determinar desta forma a influência do tratamento superficial empregado.

É necessário ressaltar, contudo, que a origem das células (coelho, rato, etc.) e o meio de cultura utilizado (F12, PBS, soro bovino) variaram entre os diferentes artigos estudados. Esta consideração é importante devido ao fato do meio de cultura poder favorecer a proliferação das células utilizadas [13].

A comparação entre os resultados de osseointegração obtidos pelos diferentes artigos é complexa, visto que vários parâmetros são modificados simultaneamente. Neste contexto, é ressaltada a importância deste trabalho como uma ferramenta que reúne, para avaliação, as variáveis dos parâmetros de superfície e os resultados obtidos pela cultura celular.

\section{CONCLUSÃO}

O desenvolvimento de uma base de dados que ajude a compreender a influência do tratamento de superfície no $\mathrm{Ti} / \mathrm{TiO}_{2}$, é complexo. Mesmo com a utilização de filtros que delimitem a busca de artigos, diversos parâmetros são modificados em cada

* Contribuição técnica ao 69 Congresso Anual da ABM - Internacional e ao 14ํㅡㄹ ENEMET - Encontro Nacional de Estudantes de Engenharia Metalúrgica, de Materiais e de Minas, 21 a 25 de julho de 2014, São Paulo, SP, Brasil. 


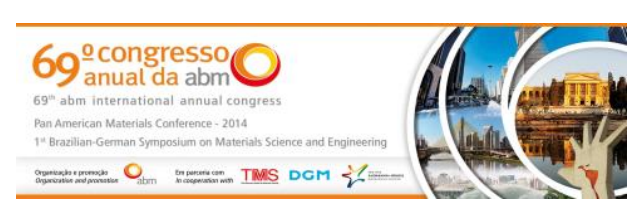

estudo, dificultando a correlação dos resultados obtidos por um autor em relação aos resultados obtidos por outros autores.

O presente trabalho coloca em evidência aspectos que podem inclusive comprometer a comparação de resultados que descrevem o desempenho das superfícies, como é o caso da composição da solução empregada na cultura de células. Fatores como esse, dentre outros aqui evidenciados, podem comprometer o direcionando dos pesquisadores na escolha do tratamento de superfície adequado.

\section{Agradecimentos}

Os autores agradecem a Faculdade SATC pela apreciável contribuição dos recursos para o desenvolvimento desse trabalho.

\section{REFERÊNCIAS}

1 Lima GG. Propriedades mecânicas e de biotividade de filmes anódicos de titânio, contendo íons de $\mathrm{Ca}$ e $\mathrm{P}$, submetidos a tratamentos térmicos e de hidrotérmicos. Paraná: Universidade Federal do Paraná; 2012.

2 Almeida Filho E. Assis CM; Vercik LO, Guastaldi AC. Biomateriais: deposição de hidroxiapatita sobre superfície de Ti-cp modificada por aspersão térmica. Quím. Nova [online]. 2007: 30(5): 1129-1232. ISSN 0100-4042.

3 Feng B, Weng J, Yang BC, Qu SX, Zhang XD. Characterization of surface oxide films on titanium and adhesion of osteoblast. Biomaterials. 2003; 24: 4663-4670.

4 Györgyey A, Ungvári K, Kecskeméti G, Kopniczky J, Hopp B, Oszkó A, Pelsöczi I, Rakonczay Z, Nagy K, Turzó K. Attachment and proliferation of human osteoblast-like cells (MG-63) on laser-ablated titanium implant material. Materials Science and Engineering: C, 2013; 33: 4251-4259.

5 ScienceDirect. Elsevier. 2014 [acesso em 20 fev. 2014]. Disponível em: http://www.sciencedirect.com/.

6 Neupane MP, Park IS, Bae TS, Yi HK, Watari F, Lee MH. Biocompatibility of TiO2 nanotubes fabricated on $\mathrm{Ti}$ using different surfactant additives in electrolyte. Materials Chemistry and Physics, 2012; 134: 536-541.

7 Hori N, Iwasa F, Ueno T, Takeuchi K, Tsukimura N, Yamada M, Hattori M, Yamamoto A, Ogawa T. Selective cell affinity of biomimetic micro-nano-hybrid structured TiO2 overcomes the biological dilemma of osteoblasts. Dental Materials, 2010; 26: 275-287.

8 Qu C, Myllymaa S, Prittinen J, Koistinen AP, Lappalainen R, Lammi MJ. Osteoblast behavior on various ultra short pulsed laser deposited surface coatings. Materials Science and Engineering: C, 2013; 33: 1676-1682

9 Sugita $Y$, Ishizaki K, Iwasa F, Ueno T, Minamikawa H, Yamada M, Suzuki T, Ogawa T. Effects of pico-to-nanometer-thin $\mathrm{TiO} 2$ coating on the biological properties of microroughened titanium. Biomaterials. 2011; 32: 8374-8384.

10 Brammer KS, Oh S, Cobba CJ, Bjurstenb LM, Heydec HVD, Jin S. Improved boneforming functionality on diameter-controlled TiO2 nanotube surface. Acta Biomaterialia, 2009; 5: 3215-3223.

11 An SH, Matsumoto T, Sasaki JI, Miyajima H, Narayanan R, Imazato S, Kim KH. In vitro bioactivity evaluation of nano- and micro-crystalline anodic TiO2: HA formation, cellular affinity and organ culture. Materials Science and Engineering: C. 2012; 32: 2516-2522.

12 Czekanska EM, Stoddart MJ, Richards RG, Hayes JS. In Search of an Osteoblast Cell Model fo in vitro Research. European Cells and Materials, 2012; 24:1-17.

13 Brandão ML, Esposti TBD, Bisognin ED, Harari ND, Vidigal Jr. GM, Conz MB. Superfície dos implantes osseointegrados $X$ resposta biológica. Rev. Implantnews, 2010; 7(1): 95-101.

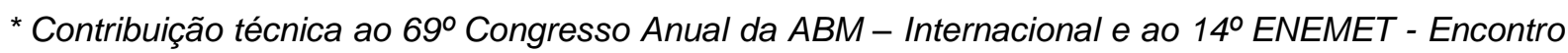
Nacional de Estudantes de Engenharia Metalúrgica, de Materiais e de Minas, 21 a 25 de julho de 2014, São Paulo, SP, Brasil.
} 